\title{
Exploring Region of Origin Labeling Food Products as a New Experiential Brand Strategy ${ }^{1}$
}

\author{
Trabelsi Trigui Imene ${ }^{1}$ and Giraud Georges ${ }^{2}$ \\ ${ }^{1}$ Faculty of Economic Sciences and Management, SFAX, TUNISIA \\ ${ }^{2}$ AgroSup Dijon, Dijon, France
}

\begin{abstract}
Food labels, and more particularly geographical indication labels, such as $\mathrm{PDO}^{2}$ or $\mathrm{PGI}^{3}$ have become increasingly frequent in response to recent food crises and technological developments such as GMO's. They are expected to offer food safety guarantees due to their traceability and authentication as well as high organoleptic qualities linked to their origin. They are likely to affect the consumer within the same manner than sensory brands do.

The purpose of this paper is to examine to what extent a food product with a region of origin label, considered as a specific sensory brand, affects consumer preferences in comparison with an official quality label such as PDO or PGI labels.

From qualitative and quantitative data analyses we conclude that food products with regional reference could affect consumer preferences with a larger extent than food products protected by official labels. Emotional experience has been found to affect the group involving those who prefer regional food products more considerably than the other factors.
\end{abstract}

Keywords: experiential marketing, Branding, Region of origin labeling, consumer preference

\section{Introduction}

As origin labels, geographical indications, have the potential to offer to the consumer experiential guarantee, in addition to the traceability and quality guarantee. They are likely to affect the consumer within the same manner than sensory brands do.
Origin labelled food products are expected to be bought and eaten not only for their functional values, such as nutritional and health benefits. In a globalized, anonymous and urban world, where one can find a large variety of exotic and imported food products, consumers seem to feel that they have lost their identities and roots.

\footnotetext{
${ }^{1}$ This paper is based on the research project TYPIC (Typical Food Products in Europe: Consumer Preference and Objective Assessment) supported by the European Commission DG Research (contract $\mathrm{n}^{\circ}$ QLK1-CT-2002-02225), see website www.typic.org.
}

2PD0: Protected Designation of Origin, food products which are produced, processed and prepared in a same and specific region. Only these products are allowed to carry the specified name, since the quality of these products can be attributed to the region denoted by the name.

3PGI: Protected Geographical Indication, these products are produced or processed or prepared in the specified region.

Copyright (C) 2012 Trabelsi Trigui Imene and Giraud Georges. This is an open access article distributed under the Creative Commons Attribution License unported 3.0, which permits unrestricted use, distribution, and reproduction in any medium, provided that original work is properly cited. Contact author: Trabelsi Trigui Imene E-mail: imentrigui@yahoo.fr 
Origin food labels could respond to this need to find again roots or to remember happy holidays in a rural area (Giraud, 2004) or even dreamt childhood. The historical, cultural, and sensory content (flavour and taste) of origin labelled foods could have a large effect on consumer emotions, by eliciting feelings of homesickness for the good old days, stimulating enjoyment and pleasure. Moreover, origin labelled food products include symbolic and social dimensions that could influence consumer attitudes and behaviour towards these products. By choosing these products, customers could identify their consumption with the area of production and express their need to feel closer the product's region of origin. Consumers seem to be not only variety seekers but also identity seekers.

The objective of our study is to examine the effect of these specific sensory brands (origin food labels) on the emotional experience of consumers.

Our paper will be divided into four parts: 1Brief literature revue on the new experiential view to branding and to region of origin values; 2- Conceptual model from which hypotheses are formulated; 3Research methodology (sample, original consumer surveys, statistical measurements); 4- Results, discussion and marketing implications.

\section{Literature Review, the New Experiential View to Branding}

Since the mid-1980s, consumer behaviour researchers and practitioners have considered customers as only rational decision makers and thus have largely neglected vital psychological human traits as emotions, feelings and sensory aspects.
This aspect of consumer research has been widely criticised by several researchers (Holbrook and Hirschman, 1982; Shiv and Fedorikhin, 1999). The new experiential view (Holbrook and Hirschman, 1982), which is complementary to the traditional cognitive view, has considered consumers not only thinkers and doers, but also feelers, social and emotive ones (Addis and Holbrook, 2001).

Nowadays, one could easily notice the emergence of new and more sophisticated community of consumers who not only demand products of a highest quality, but also insist on positive, emotionally sensitive, memorable and original experiences (Barlow and Maul, 2000). Consequently, scientific and managerial interests in the concept of sensorial pleasure and its role in consumption experiences have noticeably increased lately.

Within the greater competition, variety and choice in many food markets induced by the economic globalisation and internationalisation, intangible benefits such as brand image and consumption experiences are becoming more important than tangible benefits such as price and food quality cues (e.g. freshness, healthy and safe ingredients) (Gray et al. 2003). However, this does not mean that competitive prices and quality cues are no longer important product attributes. They are considered as givens and minimum standards but unfortunately they remain insufficient to differentiate one company from its competitors.

Pine and Gilmore (1999) recently argued that careful attention to the experiential dimension of goods and services could be a profitable source of differentiation and 
competitiveness in markets that have become commoditized.

Schmitt (1999) quoted many examples of companies providing memorable experiences and offered one framework for designing managing experiential marketing through four principal components: sense, feel, think, act and relate experiences.

Schmitt (1999) considers that "the traditional approach to branding treats a brand as a static identifier of a company's products through the use of names, logos and ad slogan.... But brands are not just identifiers. Brands are first and foremost providers of experiences".

More particularly marketing aesthetics (Schmitt and Simonson, 1997), referring to the marketing of sensory experiences in corporate or brand output that contributes to the organization's or brand's identity, seems to offer a new approach to branding.

Pearson (1996) considers a brand as a combination of features (what the product is), customer benefits (what the product does), and values (what the customer associates with the product. Keller (1993) presents brand image as perceptions about a brand as reflected by the brand associations held in consumer memory. Preferences towards brands are the outcome of the emotional needs consumers have. Emotional associations have a stronger effect on differentiating one product from its competitors in consumer's mind. Branding strategies are likely to transform functional assets into relationship assets (Ghodeswar, 2008; Achouri and Bouslama, 2010).

Aaker (1991) says image creates value in a variety of ways, helping consumers to process information, differentiating the brand, generating reasons to buy, giving positive feelings, and providing a basis for extensions. Brand associations are all the linkages that exist between a brand and the other modes stored in memory. In measuring the structure (how information related to a brand is organized in memory) and the content (i.e. brand associations) of knowledge that a consumer holds for a brand, the perception the consumer has of the brand is also measured (Korchia, 1999).

This view is consistent with the belief that knowledge is organized into sets of information (Mitchell, 1982). Nevertheless, brands are not only static markers that imply ownership and quality signs leading to memorable names, logos and great image. They are also dynamic and rich sources of sensory, affective and cognitive associations that result in memorable brand experiences (de Chernatony, 2010).

\section{Region of Origin Labelling, a New Sensory Brand Strategy}

According to Brakus, Schmitt and Zarantonello, (2009), brand experience refers to "sensations, feelings, cognitions, and behavioral responses evoked by brandrelated stimuli that are part of a brand's design and identity, packaging, communications, and environments"

In fact, within an experiential perspective, products need to relate the brand to something the consumer cares about and significantly affects him/her both with sensorial and emotional manners. In this context, food quality labels, such as region of origin, defined, as sensory brandscautions could, besides fulfilling the same objectives of ordinary brands (differentiation from competitiveness, protection from imitations, ownership and brand image guarantees), deliver experiences that affect considerably and more durably consumer emotions and behaviour.

Since customers increasingly become variety-seekers, producers and distributors have taken into account actual customer concerns to make them loyal. Marketers, knowing the important role that they can play in bringing distinctiveness to their brands, have given a particular attention to product and package design (Veryzer and Hutchinson, 1998), and the sensory visual elements that comprise them (Garber et al. 2000). One powerful visual element, which may induce a variety of associations to consumers, is the brand logo. It is known to 
serve as a particularly vivid, affect-loaded and memorable visual cue. It is also the most crucial semiotic mediator for meaning within a company's verbal and visual promotion strategies. Floch (1988) argues that logos must express differences so that customers can easily recognise one company from another within a current marketplace.

The brand logo is a combination of three major elements: the design, the colours and the logo content corresponding to the brand name of the product. For some types of food products, the brand name is associated with the region of origin. This strategy, branding with a regional reference, is one of possible image transfer strategies that companies may choose. Two different ways can be used with the attribute region of origin:

\section{Region of Origin Label}

Food labels and more particularly designation of origin labels, such as PDO or PGI, have become increasingly frequent and apposed to a large variety of food products, in response to recent food crises and technological developments such as GMO's. They are expected to offer food safety guarantees due to their traceability and authentication as well as high organoleptic qualities linked to their origin.

Producers may obtain the suitable official label by an independant certification institute, provided that they passed the quality control necessary for assuring production process respect to some specific norms and corresponding conditions (Bertozzi, 1995).

Origin labels are generally considered as additional extrinsic cues among other intrinsic and extrinsic cues (Zeithmal, 1988) on which consumers base their quality perception of the food product. They are perceived to provide technical or nutritional information and assuring functional benefits similar to those offered by generic products. Thus, the label doesn't seem to constitute an important choice criterion on which consumers base their decisions.
Only few consumers perceive the particular sensory qualities of region of origin food products and are willing to pay a premium price for purchasing them. Consequently, some producers aware of the existence of an information asymmetry between them and consumers have tried to adopt another positioning strategy: the brand with a regional reference.

\section{Brand with Regional Reference}

Many SMEs have positioned their products by choosing the regional reference associated with their brand name. Different motives for and benefits of marketing products based on the region of origin can be pointed out (Van Ittersum, 2003).

Consumers' preference for regional food products is growing. Thus a lot of companies are benefiting from this large demand by introducing and marketing regional products.

The use of a well-known region of origin may be a better strategy of product differentiation than the development, introduction and positioning of a brand name. Branding is a long and expensive process. Consumers use their associations with the product's region of origin to infer their expectations regarding the overall quality of the regional product. These associations could help firms to provide their product with an image, rather than to be created. We expect that more nostalgic consumers are, more this branding strategy, consisting on associating to the brand a regional reference is likely to affect consumer preferences more significantly. Emotional experience could have a discriminant effect on two groups of consumers: those who prefer a product with an official label, perceived as a product informing consumers about its respect to some norms of security. The second group includes consumers who are more sensitive to the origin of the product and having affective associations and connotations within this origin, than the label itself.

In order to examine consumer preferences towards these positioning product 
strategies and the different values associated to them, we have adopted two different consumer surveys: a qualitative research in order to investigate the salient attributes on which consumers base their decision choice and to explore consumers associations, beliefs and values towards food products differing according to their origin. Then, a quantitative consumer survey was adopted aiming at identifying the factors that are likely to affect consumer preferences towards these products.

\section{Research Methodology, Qualitative Consumer Survey (Focus Group)}

Dry-cured ham was chosen for two main reasons. The region on which consumer survey was made "Auvergne", (France) is known for dry-cured ham production. The geographic and cultural proximity of the product and consumers is likely to facilitate discussions about it. The consumption of dry-cured ham in France and in Europe has suffered from a decline during the last few years. Examining the attributes on which consumers base their choice may allow understanding the main motivations and inhibitors for purchasing dry-cured ham.

Qualitative research methods are known to provide techniques for data generation (Treagar et al. 1997), particularly, exploratory focus group discussions. The focus group on dry-cured ham, involving eight participants with different sociodemographic profiles, was conducted through the use of a discussion topic guide. Two main objectives were fixed: obtaining some preliminary insights in the most relevant attributes that consumers take into account when they are in situation of purchasing this product and extracting consumers' beliefs and values associated to both regional reference and region of origin label.

Participants have quoted different criteria as the main attributes on which they refer when making their purchase of dry-cured ham.

Two different types of criteria categories on which consumers base their choices are distinguished. Intrinsic characteristics are linked to the product sensory characteristics (aspect, taste, appearance and color of the dry-cured ham). Extrinsic characteristics deal with marketing attributes, involving all kinds of information found on the packaging relative to the product composition, its origin or provenance, its brand name, the existence or not of a label, the packaging characteristics, the merchandising on shelves and price.

These findings are similar to those of other studies dealing with the factors affecting consumer food product choices (Shepherd, 1990; Randall and Sanjur, 1981).

Although all food product attributes are perceived as important by participants, origin of the chosen product seems to be the most important attribute on which they base their purchase decision. Participants attribute to the origin dimension different beliefs and values. However, the existence or not of a label on the packaging was not considered by participants as a criterion on which they build their choice. They seem to be not aware of its significance and they show a great confusion according to characteristics and meanings of the different types of labels. Origin labelled food products aren't perceived as products having particular organoleptic and sensory qualities similar to those offered by the regional reference, known by its particular product quality.

Following the theory of consumption values, three different values of dry-curedham according to its origin have been distinguished: emotional value, sensory value and social value.

The elicited consumers' motives for preferring food products coming from their own region of origin are:

- Emotional Motives. Regional products arouse positive feelings of happiness and less homesickness since they are strongly associated with the origin of consumer or with the memory of pleasant experiences in the product's region of origin. 
- Sensory Motives. Since regional products are considered as typical products, they are perceived as having "attractive" and "appealing" appearance (aspect, color) and specific texture, which have an effect on their flavor and taste.

- Social Motives. Regional products help to support local producers. They express a kind of belonging with the product's region of origin.

The preliminary finding issued from this focus group discussion is that consumers give a lot of importance to regional food products since they offer social, emotional and sensory values. Thus three types of motivations or factors could explain consumer preference of region of origin food products: social, emotional and sensory factors. These factors have been also found by several studies as influencing consumer behavior towards food products (Van Ittersum, 2003; Gray et al. 2003).

Since consumer survey was made in a specific region, known by its typical drycured ham, regional preferences of the participants may be explained by their involvement on this product. For this reason, consumer involvement could be an additional explanatory factor of preferring region of origin food products (Skuras and Vakrou, 2002).

\section{Quantitative Consumer Survey}

Consumer preferences were generally measured by simply asking consumers in the questionnaire about their preferences. Thus, respondents have to make a cognitive effort to evaluate their preferences, which may be different from those expressed when they are in a purchase situation (Köster, 2003). To avoid this bias, and as suggested by authors who approve the experiential view of consumption (Holbrook and Hirschman, 1982; Schmitt, 1999; Hetzel, 2002), an experiential technique was used to measure this construct. It consists with ranking, by order of preference, three different dry-cured ham sets.
Set 1 contains three packages of dry-cured ham from the region of Bayonne with a PGI label. The whole set (3x100 gr.) has a price of 6 Euros. Bayonne is a famous region for dry-cured ham in Europe (France), but far away from the region where the survey was located.

Set 2 contains two packages of dry-cured ham with a regional reference to Auvergne (the region where the survey takes place). The price of this whole set ( $2 \times 100 \mathrm{gr}$.) is also 6 Euros.

Set 3 contains only one package of foreign dry-cured ham from Teruel (Spain). The price of set 3 (1x100 gr.) is again 6 Euros.

Doing so, we propose to consumers different quantities and prices of dry-cured ham, in order to put them very close to the purchase situation.

The concept of food involvement has been extensively investigated (Olsen, 2001; Pliner and Hobden, 1992; Juhl and Poulsen, 2000; Bell and Marshall, 2003). Food, as a product category, was classified as being of low involvement because of the low cost of food relative to an individual's or family's total income. However, as stated earlier, food consumption is influenced both by cognitive motives related to the individuals' health and safety concerns and by affective motives in relation within the pleasure, the emotional states and the social values that food purchase and consumption may arouse. For this reason, authors have taken into account these two dimensions in measuring the involvement concept.

Strazzieri, (1994) has developed the PIA scale with three main dimensions:

Pertinence (relevance) is the relation power existing between and individual values and product category

Interest is the cognitive relation power

Attractiveness is the emotional relation power. 
This scale has been found having satisfactory reliability and validity. We have adapted this scale to our study objectives. After being tested and evaluated, the final version of the scale (a Likert scale, ranking from I totally disagree to I totally agree) contains the following items:

A food product with a region of origin label is a product:

- To which I attach a particular importance

- That accounts a lot for me

- In which I have a lot of interest

- About which I like tell with my friends

- Which particularly attracts me.

- Which purchase is a pleasure.

\section{Emotional Values}

Since purchase of food is seldom an extensive decision, which is less or more limited, familiarized and driven by impulses, cognitive control is not very high. Thus, the role of affective factors may be more important in consumer purchase motives than cognitive motives. Consumers may choose particular products or brands not only because these products provide the functional or performance benefits expected, but also, because products can be used to fulfill consumers' internal psychological needs and affective purposes (Kim et al. 2002).

Richins (1997) has developed a new measurement for emotional experience, the Consumption Emotion Set scale. According to Schmitt (1999), Richins' typology is the best typology compared to the others. It covers the emotions that are most commonly experienced in a variety of consumption situations including food purchase. The measures are statistically reliable and brief. Additionally, the terms used in the scale are familiar could be easily understood by consumers.

Consequently, as the CES presents a lot of advantages and is more suitable for food products, we have decided to adopt it for measuring emotional experience towards regional food products. However, before putting it on the final questionnaire, we have tested the scale during the focus group, in order to be sure of its relevance to our study objectives. Consequently, several items have been found insignificant and were omitted in the final questionnaire. The final relevant scale ranging from I don't feel this emotion at all to I strongly feel this emotion contains the following:

When I purchase a food product with a regional reference: I don't feel this emotion at all to I strongly feel this emotion:

- Homesick
- Happy

- Satisfied.

\section{Sensory Values}

Sensory cues have been found in many studies to exert a great influence on consumer emotions and preferences (d'Hauteville, 2003; Cardello, 1996).

According to Cardello (1996), most sensory stimuli, especially food products, elicit a hedonic dimension. This hedonic dimension is inherent in all sensory stimuli, involving those arousing olfactory, gustatory sensations.

Consequently, after applying Churchill paradigm (Churchill, 1995) to assess psychometric qualities of the proposed scale (items purification and reliability testing), the final version of the scale (Likert scale ranging from totally disagree to totally agree) used to measure sensory values, by means of «perceived typicality» of regional products, covers the following items:

A food product with a region of origin label is a product:

- That fabrication preserves regional traditions

- Having specific taste due to its region of origin

- Which offers an original taste. 


\section{Social Values}

In addition to emotional purposes, consumers may choose products or brands for fulfilling social objectives, such as expressing their personality, social status or affiliation. (Kim et al. 2002). Schmitt refers to social values as «relate experiences», the fifth component of experiential marketing in addition to the emotional, sensory, and cognitive and act experiences.

Supporting local producers, as stated by some participants during the focus group survey may be another social motive for preferring regional products to national, even labelled, products. Conviviality may be also a fourth social motive to purchase and consume regional food products. Many authors have suggested that conviviality is one social value of food consumption having an important influence on consumer purchase behaviour (Sirieix, 1999; Poulain, 2002; Holt, 1995; Fishler, 1993).

Consequently, the final version of the scale, after item purification, serving to measure social values of regional products involves the following items:

\section{A food product with a region of origin label is a product:}

- Which allows me to preserve my identity.

- Which consumption is often shared with others (friends, family).

- That favours conviviality.

\section{Data Analysis}

A sample involving 113 consumers, chosen from a scanned panel was selected for the final consumer survey. The questionnaire was first tested in order to determine its potential effectiveness and to avoid mistakes in questionnaire design. Data analysis was established by using three main statistical methods: Exploratory factor analysis, Descriptive frequency data analysis and Discriminant analysis.

All factors show a value of measure of sampling adequacy (MSA) superior to 0.5 .
Consequently, factor analysis is an appropriate tool in these circumstances.

Principle components factor analysis, with a varimax rotation was the method used to examine the whole range of interrelated relationships in the data sets. Principle component factor analysis aims to convert a set of interrelated variables into a number of unrelated linear combinations of these variables (Churchill, 1995). Furthermore to obtain the most adequate interpretation of the variables under investigation, rotation is encouraged as it can simplify the factor structure.

Having demonstrated that each of the ten derived factors form coherent groups of associated variables, it is also important to test their validity and reliability. The internal reliability of each factor was, therefore, examined using coefficient 'Alpha' (Hair et al., 1997). Alpha scores should exceed 0.70 , although scores of 0.60 and above are acceptable (Evrard et al. 1997).

A factor analysis using principle component extraction, with varimax rotation, was used as a mechanism for summarising and reducing the data in each of the two sets of variables. The application of the 'Scree' test and a review of the 'Eigen' values (Hair et al. 1995) were used to determine the most statistically significant number of factors for each of the variable sets. Ultimately, all factors have been found to be unidimensional, except two. Factor "perceived typicality" used to measure sensory cues was split. Factor 1 involves three items. Factor 2 was composed by one item. Thus we have decided to omit it. The factor "Involvement" was also split. Factor 3 involves the first three items (to which I attach a particular importance; that accounts a lot for me; in which I have a lot of interest) and will be named "Interest". Factor 4 involves the last three last items, is named "Pleasure". The final factorial structure is shown in Appendix 1.

The frequencies' classification of the three types of sets was examined. Descriptive statistics provided by SPSS software, has leaded to the following table for the three sets. 
Table 1: Consumer Ranking Sets of Dry-Cured Ham according to Region of Origin

\begin{tabular}{|l|c|c|c|}
\hline Rank & $\begin{array}{c}\text { Set 1 } \\
\text { far away region }\end{array}$ & $\begin{array}{c}\text { Set 2 } \\
\text { local region }\end{array}$ & $\begin{array}{c}\text { Set 3 } \\
\text { foreign region }\end{array}$ \\
\hline 1 & $19.3 \%$ & $43.8 \%$ & $36.9 \%$ \\
\hline 2 & $21.3 \%$ & $26.8 \%$ & $51.9 \%$ \\
\hline 3 & $57.9 \%$ & $29.7 \%$ & $12.4 \%$ \\
\hline
\end{tabular}

Set 2 corresponding to dry-cured ham from Auvergne (local region) was the most preferred followed by Set 3 which corresponds to dry-cured ham of Teruel (foreign region). Finally Set 1 including dry-cured ham from Bayonne (far away region) was ranked at least.

In order to examine the factors and the motivations that are likely to distinguish between (group 1) those who prefer regional food product (consisting with drycured ham of Auvergne, the most preferred by consumers), and those who aren't (group 2) (those who prefer other origin of dry-cured ham) discriminant analysis is applied.

Independent factors are: Involvement, emotional values, social values and sensory values.

To use discriminant analysis, four main conditions should be respected:

- Data normality. This condition is respected since the number of observations for each group exceeds the value of 30. (32 for group 1 and 81 for group 2).

- Equality of variance-covariance between the groups. This condition was verified by means of multivariate test $M$ Box. The risk to reject $\mathrm{H}_{0}$ (equality of variancecovariance matrix) is high (0.24) (Appendix 2).

- Existence of means differences between the two groups. This condition was tested and verified by means the weak value of Wilk's Lambda and also the high value of Chi 2 presenting a null value of significance (Appendix 3).

- Absence of multicolinearity. This condition is surpassed since factors included in this study are issued from a factor analysis.

Stepwise discriminant analysis allows to obtain coefficients of the discriminant function, and consequently, discriminatory factors.

Tableau 2: Canonical Discriminant Function Coefficients

\begin{tabular}{|l|l|}
\hline Interest & 0,305 \\
\hline Pleasure & 0,502 \\
\hline Perceived typicality & 0,804 \\
\hline Homesickness & 0,911 \\
Happiness & 0,322 \\
Satisfaction & 0,489 \\
\hline
\end{tabular}


Hair et al. (1997) suggested that 'all variables entered into the function, and generally any variables exhibiting a loading of \pm 0.30 or higher are generally considered substantive'. This table shows that all these factors, with more or less stronger effect, discriminate between the two groups: those who prefer regional food products.

The emotional factor "Homesickness", was found the factor having the stronger discriminatory effect between the two groups. The overall percentage of cases correctly classified is $61.6 \%$. In order to determine whether this level of predictive accuracy is statistically significant, the proportional chance criterion $\left(\mathrm{C}_{\mathrm{PRO}}\right)$ was calculated. $\mathrm{C}_{\mathrm{PRO}}(52.5 \%)$ is inferior to $61.6 \%$. Thus the predictive quality of the function can be considered as good.

\section{Results and Marketing Implications}

From qualitative and quantitative data analyses, we conclude that food products with regional reference could affect consumer preferences with a larger extent than food products protected by official labels.

Emotional experience has been found to affect the group involving those who prefer regional food products more considerably than the other factors. Therefore this finding confirms the experiential view of consumption, which focuses particularly on the importance of the emotional experience (Holbrook, 1986; 1999).

Although, official labels were aimed to increase quality perception of food products by consumers, they still remain misunderstood and underestimated (Grunert et al. 2001). The reason could be related to consumers' perceptions. Consumers may appreciate labels only from the cognitive perspective. Labels are seen as generic norms that firms should respect in order to protect products from imitation and to guarantee their authentication and traceability. Consumers seem to be not interested by these norms, which are perceived relevant only to the firms engaged on the labelling strategies. Thus a communication strategy to increase consumer awareness about the values offered by food labels could be fruitful.

What consumers seem to be looking for is satisfying both their psychological, sensorial and emotional expectations more than functional or utilitarian ones. Thus firms, already involved in labelling strategies should take a more emphasis on emotional and sensory benefits of labels than utilitarian aspects. More particularly, since consumers could develop memorable associations with brands, it will be useful for firms to associate a region of origin reference to the label. In this case, labels could offer to consumers both functional and experiential benefits as sensory brands do.

Our findings are also relevant for companies looking for giving experiential values to their brands. Firms who suffer from a decline of their brand image could enhance their notoriety by adopting a new approach to branding consisting on positioning their products by choosing the regional reference associated with their brand name. The use of a well-known region of origin may be a more efficient device for differentiating products than the development, introduction and positioning of a brand name, based on a set of associations. The associations that consumers have within the different regions are likely to help marketers to provide their product with an image, rather than to be created. Consequently, consumers use their associations with the product's region of origin to infer their expectations regarding the performance and the different values of the regional product.

\section{References}

Aaker, D. A. (1991). 'Managing Brand Equity,' New York: The Free Press.

Achouri, M. A. \& Bouslama, N. (2010). "The Effect of the Congruence between Brand Personality and Self-Image on Consumer's Satisfaction and Loyalty: A Conceptual Framework," IBIMA Business Review, Volume 2010, 17 pages. 
Addis, M. \& Holbrook, M. (2001). “On the Conceptual Link between Mass Customisation and Experiential Consumption: An Explosion of Subjectivity," Journal of Consumer Behaviour, vol.1, 1, 50-66.

Barlow, J. \& Maul, D. (2000). 'Emotional Value: Creating Strong Bonds with Your Customers,' The Journal of Business and Industrial Marketing, Vol. 15(6), 458-460.

Bell, R. \& Marshall, D. W. (2003). "The Construct of Food Involvement in Behavioural Research: Scale Development and Validation," Appetite, Vol. 40, 235-244.

Bertozzi, L. (1995). “Designation of Origin: Quality and Specifications," Food Quality and Preference, 6, 143-147.

Brakus, J. J., Schmitt, B. H. \& Zarantonello, L. (2009). "Brand Experience: What is it? How is it Measured? Does it Affect Loyalty?," Journal of Marketing, Vol. 73, No. 3, pp. 5268.

Cardello, A. (1996). 'The Role of the Human Senses in Food Acceptance,' Food Choice, Acceptance and Consumption, H.L. Meiselman, H.J.H. Mac-Fie eds, Londres, Blackie Academic \& Professional, 1-82.

Churchill, Gilbert A. Jr. (1995). Marketing Research, Methodological Foundations, The Dryden Press.

De Chernatony, L. (2010). 'From Brand Vision to Brand Evaluation,' Oxford : Butterworth-Heinemann.

D'Hauteville, F. (2003). "Processus Sensoriels et Préférence Gustative: Apports de la Recherche Expérimentale au Marketing Agro-Alimentaire," Revue Française de Marketing, ${ }^{\circ}$ 194, 13-27.

Evrard, Y., Pras, B. et Roux, E. (1997). 'Market: Etudes et Recherches en Marketing,' Edition Nathan, France.

Fischler, C. (1993). 'L'homnivore,' 2nd ed. Editions Odile Jacob, Paris.

Floch, J-M. (1988). "The Contribution of Structural Semiotics to the Design of a
Hypermarket," International Journal of Research in Marketing, 4, 233-252.

Garber Jr. L. L., Hyatt, E. M. \& Starr, Jr R. G. (2003). "Measuring Consumer Responses to Food Products," Food Quality and Preference, Vol.14, 3-15.

Ghodeswar, Bhimrao M.(2008). "Building Brand Identity in Competitive Markets: A Conceptual Model," Journal of Product \& Brand Management, 17/1, 4-12.

Giraud, G. (2004). 'Consumer Perception and Marketing of Organic Labelled Food Products in Europe,' In Marketing Trends for Organic Food in the Advent of the 21st Century, G. Baourakis editor, World Scientific Publishing Co press, 218-230.

Gray, B., Bell, J. \& Ponsonby, S. (2003). “Are You in Mood...for Food?," Journal of Food Products Marketing, Vol. 9(1), 3-13.

Grunert, K. G., Juhl, H. J. \& Poulsen, C.S. (2001). "Perception de la Qualité en Alimentaire et Rôle des Labels," Revue Française de Marketing, $\mathrm{n}^{\circ} 183-184,3-4$, 181-196.

Hair, J., Anderson, R. E., Tatham, R. L. \& Black, W. C. (1992). 'Multivariate Data Analysis with Readings,' 3rd ed., Maxwell Macmillan Publishing, Singapore.

Hetzel, P. (2002). 'Planète Conso: Marketing Expérientiel et Nouveaux Univers de Consommation,' Paris, Ed. Organisation.

Holbrook, M. B. (1986). "Emotion in the Consumption Experience. Towards a New Model of the Human Consumer," The Role of Affect in Consumer Behavior, Emerging Theories and Applications, Peterson R.A., Hoyer W. D. \& Wilson W. R. (eds). Toronto, MA, Lexington Books, 17-52.

Holbrook, M. B. (1999). 'Consumer Value,' Routledge, NY.

Holbrook, M. B. \& Hirschman, E. C. (1982). "The Experiential Aspects of Consumption: Consumer Fantasies, Feelings, and Fun," Journal of Consumer Research, 9, 132-140. 
Holt, D. B. (1995). "How Consumers Consume: A Typology of Consumption Practices," Journal of Consumer Research, 22 (June), 2-16.

Juhl, H. J. \& Poulsen, C. S. (2000). "Antecedents and Effects of Consumer Involvement in Fish as a Product Group," Appetite, 34(3), 261-267.

Keller, K. L. (1993). “Conceptualising, Measuring, and Managing Customer-Based Brand Equity," Journal of Marketing Research, 29, 1-22.

Kim, J-O, Forsythe, S., Gu, Q. \& Moon, S. J. (2002). "Cross-Cultural Consumer Values, Needs and Purchase Behavior," Journal of Consumer Marketing, Vol.19, n6, 481-502.

Korchia, M. (1999). 'A New Typology of Brand Image,' European Advances in Consumer Research, Vol. 4, 147-154.

Köster, E. P. (2003). "The Psychology of Food Choice: Some often Encountered Fallacies," Food Quality and Preference, Vol. 14, 359-373.

Mitchell, A. A. (1982). "Models of Memory: Implications for Measuring Knowledge Structures," Advances In Consumer Research, 9, 945-951.

Olsen, S. O. (2001). "Consumer Involvement in Seafood as Family Meals in Norway: An application of the expectancy-value approach," Appetite, 36(2), 173-186.

Pearson, S. (1996). 'Building Brands Directly: Creating Business Value from Customer Relationships,' Macmillan Business, Houndmills/London.

Pine, B. J. II \& Gilmore, J. H. (1999). The Experience Economy, Boston, MA, Harvard Business School Press.

Pliner, P. \& Hobden, K. (1992). "Development of a Scale to Measure the Trait of Food Neophobia in Humans," Appetite, 19, 105-120.

Poulain, J-P. (2002). 'Manger Aujourd'hui, Attitudes,' Normes et Pratiques, éds Privat, Toulouse.
Randall, E. \& Sanjur, D. (1981). "Food Preferences - Their Conceptualization and Relationship to Consumption," Ecology of Food and Nutrition, 1, 151-161.

Richins, M. L. (1997). "Measuring Emotions in the Consumption Experience," Journal of Consumer Research, 24, September, 127-46.

Schmitt, B. H. (1999). 'Experiential Marketing: How to Get Customers to Sense, Feel, Think, Act, Relate to Your Company and Brands,' The Free Press, New York.

Schmitt, B. H. \& Simonson, A. (1997). Marketing Aesthetics. The strategic Management of Brands, Identity and Image, The Free Press, New York.

Shepherd, R. (1990). "Overview of Factors Influencing Food Choice," Proceedings of the 12th British Nutrition Foundation Annual Conference, éds. M. Ashwell, London: BNF, 12-30.

Shiv, B. \& Fedorikhin, A. (1999). "Heart and Mind in Conflict: The Interplay of Affect and Cognition in Consumer Decision Making," Journal of Consumer Research, 26, December, 278-305.

Sirieix L. (1999). "La Consommation Alimentaire: Problématiques, Approches et Voies de Recherche," Recherche et Applications Marketing, 14, 3, 41-58.

Skuras, D. \& Vakrou, A. (2002). "Consumers's Willingness to Pay for Origin labelled Wine; A Greek Case Study," British Food Journal, Vol.104, n¹1, 898-912

Strazzieri, A. (1994). "Mesurer l'implication Durable Vis à Vis d'un Produit Indépendamment du Risqué Perçu," Recherches et Applications en Marketing, Vol.9, n¹, 73-91.

Treagar, A., Kuznesof, S. \& Moxey, A. (1997). "Marketing Regional Foods in the UK: An Exploratory Consumer Study," in Typical and traditional productions: Rural effect and agro-industrial problems. 52nd EAAE Seminar-Parma, June, 19-21. 
13 Journal of Marketing Research \& Case Studies

Van Ittersum, K. (2003). 'The Role of Region of Origin in Consumer DecisionMaking and Choice,' Doctoral thesis, University of Wageningen, NL.

Veryzer, R. W. \& Hutchinson, J. W. (1998). "The Influence of Unity and Protypicality on Aesthetic Responses to New Product Designs," Journal of Consumer Research, 24, March, 374-394.

Zeithmal, V. A. (1988). "Consumer Perceptions of Price, Quality and Value: A Means-End Model and Synthesis of Evidence," Journal of Marketing, Vol.52, July, 2-22. 
Appendix 1: Final Factorial Structure after Item Purification

\begin{tabular}{|c|c|c|c|c|c|c|c|}
\hline$(\%)$ & $\begin{array}{c}\mathrm{F} 1 \\
85,1\end{array}$ & $\begin{array}{c}F 2 \\
82,2 \\
\end{array}$ & \begin{tabular}{|c|} 
F3 \\
83.3 \\
\end{tabular} & $\begin{array}{c}\mathrm{F} 4 \\
90.2 \\
\end{array}$ & $\mathrm{MSA}_{\mathrm{i}}$ & $\begin{array}{c}\text { I/ } \\
\text { SCT }\end{array}$ & $\begin{array}{l}\alpha \text { if item } \\
\text { deleted }\end{array}$ \\
\hline Typ1 & 0.92 & & & & 0.75 & 0.81 & 0.87 \\
\hline Тур2 & 0.94 & & & & 0.69 & 0.86 & 0.84 \\
\hline Typ3 & 0.90 & & & & 0.79 & 0.79 & 0.89 \\
\hline Sov1 & & 0.88 & & & 0.86 & 0.78 & 0.90 \\
\hline Sov2 & & 0.91 & & & 0.77 & 0.84 & 0.88 \\
\hline Inv1 & & & 0,88 & & 0.71 & 0.31 & 0.92 \\
\hline Invl2 & & & 0.85 & & 0.69 & 0.33 & 0.86 \\
\hline Invl3 & & & 0.87 & & 0.82 & 0.35 & 0.90 \\
\hline Invl4 & & & & 0.93 & 0.67 & 0.36 & 0.89 \\
\hline Invl5 & & & & 0.76 & 0.79 & 0.37 & 0.92 \\
\hline Invl6 & & & & 0.89 & 0.68 & 0.32 & 0.93 \\
\hline$\alpha$ & 0.91 & 0.97 & 0.96 & 0.95 & \multicolumn{3}{|c|}{ ( $\alpha$ Cronbach) } \\
\hline
\end{tabular}

Appendix 2: Test of Covariance-Variance Matrices for Each Group

\begin{tabular}{|ccc|}
\hline M Box & & 6,786 \\
F & Approximatively & 1,267 \\
& Significance & 0,24 \\
\hline
\end{tabular}

Appendix 3: Test of Means Equality between Groups

\begin{tabular}{|cccc|}
\hline $\begin{array}{c}\text { Function } \\
\text { test }\end{array}$ & Wilks & Khi-2 & Significance \\
1 & 0,32 & 62,442 & 0,000 \\
\hline
\end{tabular}

